\title{
MEMORIA COLECTIVA Y PATERNALISMO INDUSTRIAL. EL CASO DE LA POBLACIÓN OBRERA SOCIEDAD EXPLOTADORA DE TIERRA DEL FUEGO, PUNTA ARENAS, CHILE ${ }^{1}$
}

\author{
RODRIGO HERRERA O. a, DANIEL A. MATUS C. ${ }^{\text {, }}$ \\ DANIELA L. AMBROSETTI G. ${ }^{c} \&$ BORIS A. CVITANIC D. ${ }^{d}$
}

\section{RESUMEN}

En el marco de las expresiones de patrimonio industrial en el sur de Chile, la Sociedad Explotadora de Tierra del Fuego marcó una presencia que persiste hasta el día de hoy en la ciudad de Punta Arenas a través de la construcción, en la década de 1950, de un conjunto residencial para uso de sus obreros y empleados. Un estudio en profundidad de la Población Explotadora, a través del seguimiento de planos y archivos documentales, además de entrevistas y talleres participativos, permiten dar cuenta de un tejido social surgido al alero de una particular propuesta urbana y arquitectónica diseñada desde la empresa, el que aún permanece vivo en los discursos de memoria y recuerdos de vecinos y ex vecinos. La vigencia de este pasado en el presente de sus habitantes arroja elementos de análisis en torno a las dinámicas paternalistas en la industria nacional, que tuvieron su auge a mediados del siglo pasado y fueron decayendo paulatinamente a partir de la década de 1980.

PALABRAS CLAVE: Sociedad Explotadora de Tierra del Fuego, Población Sociedad Explotadora Tierra del Fuego, paternalismo industrial, memoria colectiva.

\section{COLLECTIVE MEMORY AND INDUSTRIAL PATERNALISM. WORKING CLASS POPULATION "SOCIEDAD EXPLOTADORA DE TIERRA DEL FUEGO", PUNTA ARENAS, CHILE}

\footnotetext{
ABSTRACT

Within the framework of expressions of industrial heritage in the south of Chile, the Sociedad Explotadora de Tierra del Fuego marked a presence that persists to this day in the city of Punta Arenas through the construction, in the 1950s, of a residential complex for the use of its workers and employees.

1 El presente artículo se inscribe dentro del proyecto CONICYT / PIA SOC 1403: Patrimonio Industrial: Formas de Habitar Colectivo en el sur de Chile. Aportes para su puesta en valor y recuperación integrada.

a Unidad de Patrimonio, Vicerrectoría de Vinculación con el Medio. Universidad de Concepción, Víctor Lamas º1140. rherrerao@udec.cl

b Departamento de Arquitectura. Universidad de Magallanes, Avda. Bulnes N01890. daniel.matus@umag.cl

c Departamento de Arquitectura. Universidad de Magallanes, Avda. Bulnes N01890. daniela.ambrosetti@umag.cl

d Departamento de Arquitectura. Universidad de Magallanes, Avda. Bulnes N01890. $\measuredangle$ boris.cvitanic@umag.cl
} 
An in-depth study of the Explotadora population, using blueprints and documentary archives, in addition to interviews and participatory workshops, gave an account of a social fabric that emerged from a particular urban and architectural proposal designed by the company, which remains alive in the memories and speeches of former and actual neighbors. The validity of this past in the present of its inhabitants informs about the paternalistic dynamics in the national industry, at their peak in the middle of the last century and that gradually declined from the 1980 s onwards.

KEY WORDS: Sociedad Explotadora de Tierra del Fuego company, Sociedad Explotadora de Tierra del Fuego housing complex, industrial paternalism, collective memory.

\section{INTRODUCCIÓN}

\section{Antecedentes históricos de la Sociedad Explotadora de Tierra del Fuego}

La ocupación económica del territorio austral, con posterioridad a los actos de soberanía instaurados por el Estado chileno dados por la fundación del Fuerte Bulnes en 1843 y el surgimiento de la ciudad de Punta Arenas en 1848, determinó un modo de utilización del territorio a partir de sus recursos naturales que llevó, en el año 1876, a la aparición de la ganadería ovina como actividad económica (Martinic, 2006, p. 605).

Inicialmente basada en pequeños productores individuales que, por medio de la modalidad de arriendos, solicitados al Gobernador local, instalaron unidades de explotación a lo largo del territorio continental utilizando las mejores áreas de pastoreo a ambos lados de la frontera. El rápido crecimiento de la actividad y su viabilidad económica estimularon a pequeños productores y el emprendimiento comercial, lo que detonó un aumento progresivo de solicitudes de terrenos, ya no a las autoridades locales sino que al gobierno central, lo que finalizó en la mayor entrega de tierras a un privado en el país (Martinic, 2006, p. 676). Las concesiones de arrendamiento otorgadas a José Nogueira, por 1.189.000 hectáreas, y a su cuñado Mauricio Braun, por 170.000 hectáreas, por parte del Presidente de la República, entre abril de 1889 y julio de 1890, fueron la base para la constitución de una sociedad que conformada tanto por capitales nacionales como británicos, ocupó y explotó, a partir del año 1893, gran parte de la Isla Grande de Tierra del Fuego: la Sociedad Explotadora de Tierra del Fuego (SETF).

Si bien la aparición de la compañía se dio hacia fines del siglo XIX circunscrita al territorio insular del que obtuvo su nombre, su vocación expansiva la llevó a adquirir, en sucesivas subastas y fusiones, predios y sociedades en la orilla opuesta del estrecho de Magallanes, así como también en la provincia de Última Esperanza. Es así como, en poco más de quince años, llegó a administrar prácticamente tres millones de hectáreas, constituyéndose en la mayor empresa ganadera de la Patagonia austral (Martinic, 2011, p. 6).

La inclusión de capitales ingleses, a pesar de su aparente minoría (Martinic, 2011, p. 10), determinó un modo de producción industrial caracterizado por la incorporación de tecnología, la especialización y jerarquización de la mano de obra y la inserción de la industria ganadera en sistemas de intercambio y mercados globales dominados por las potencias europeas (Bascopé, 2008, p. 22).

Fueron ese dominio y las redes de intercambio las condiciones que fijaron el advenimiento de un modo de producción particular, asociado inicialmente tanto a la importación de tecnología como al arribo de personas. No solo se trasladaron los avances de la industrialización desde las principales ciudades manufactureras de Inglaterra, sino que también se incorporaron ciudadanos ingleses, o de sus colonias, para la ejecución de los trabajos ganaderos.

La especialización del trabajo, asociada a la optimización y automatización de los procesos, requirió de obreros calificados e implicó una división del trabajo que tuvo un correlato espacial (Ambrosetti et al. 2016, p. 118), tanto en las unidades productivas como también en la ciudad de Punta Arenas, sede esta última de sus dependencias administrativas y logísticas.

Con el correr de los años, como consecuencia de la optimización de procesos productivos, los cambios en la economía local y global, además del término de los arrendamientos por parte del 
gobierno del Presidente Carlos Ibáñez del Campo en 1957, se produjo una serie de transformaciones en la empresa que incluyeron, entre otras, la incorporación de mano de obra especializada, pero esta vez de origen nacional. A su vez, el proceso de devolución de tierras, detonado por las reivindicaciones sociales y productivas de los habitantes de la región, trajo consigo la búsqueda de nuevos emprendimientos por parte de la SETF. Fue así que se produjo una diversificación de las inversiones de la empresa hacia el rubro del turismo, con la construcción y habilitación de hoteles y hosterías en sus estancias y en la ciudad de Punta Arenas (Martinic, 2011, p. 26).

La empresa finalizó sus operaciones y dejó de existir en 1973, sin embargo, durante la década de 1960 , se produjo una preocupación por las condiciones sociales y laborales de sus trabajadores que provocó mejoras en los equipamientos $e$ infraestructuras de los centros productivos $y$ mejoras en las condiciones de trabajo de las que obreros y empleados fueron beneficiarios. A los beneficios de pensiones de gracia para trabajadores, becas de estudio para sus hijos, asignaciones, movilización y entrega de carne, entre otros, se sumó la habilitación de escuelas, bibliotecas, postas, casinos y clubes en las distintas estancias (Martinic, 2011, p. 28) que, junto con la construcción de un conjunto habitacional para obreros de la empresa y sus familias en la ciudad de Punta Arenas (Ambrosetti et al. 2016, p. 112), constituyeron parte de este giro final en la acción de la empresa hacia sus trabajadores.

\section{La Población de la Sociedad Explotadora de Tierra del Fuego en Punta Arenas}

La Población Obrera de la Sociedad Explotadora se localiza a dos kilómetros al norte del centro de la ciudad. Pese a su denominación, que podría inducir a pensar que se trató de un grupo informal de viviendas y de un conjunto sin sus dotaciones de infraestructura sanitaria, vial y energética, se debe considerar, muy por el contrario, que fue proyectada por el arquitecto Arturo Calvo Hurtado a inicios de la década de 1950 y contó con todos los permisos municipales necesarios y las recepciones técnicas respectivas. La Población Explotadora se localizó en un área periférica de la ciudad de fuerte impronta rural, determinada tanto por las grandes dimensiones de las hijuelas disponibles como por la ausencia de viviendas y poblaciones aledañas al sector. Sobre un predio de 5,2 hectáreas, entre los años 1951 y 1952, se materializaron parcialmente las propuestas urbanas y de arquitectura tramitadas en la Dirección de Obras Municipales (DOM) de la I. Municipalidad de Punta Arenas, ejecutándose poco menos de la mitad de las viviendas originalmente proyectadas. La mitad del paño de terreno restante quedó sin edificaciones hasta 1966, momento en que fue vendido para la ejecución de otro conjunto residencial, la Población Enápolis (Ambrosetti et al. 2016), ejecutado para obreros y empleados de la Empresa Nacional del Petróleo (Fig. 1).

El tejido urbano propuesto por Calvo Hurtado se formó por una red de calles interiores que configuraron ocho manzanas, de las que cuatro corresponden a la Población Explotadora y otras cuatro corresponden a la Población Enápolis. En el centro del conjunto residencial se situó una plaza rectangular de 92,40 por 31,00 metros, denominada Plaza Tierra del Fuego (Fig. 2), que actúa como espacio público articulando ambas poblaciones y que es, y fue, con sus casi $3.000 \mathrm{~m}^{2}$, un elemento importante de la vida comunitaria. El espacio urbano generado se caracteriza por la amplitud tanto de las calles de acceso al interior de la Población Explotadora, calle Julio Lillo y ambos tramos de calle Benedicto Cárdenas, como de la red de calles interiores, que permitieron generar perfiles viales que privilegiaron la circulación peatonal a través de una acera ancha que permitió la presencia de franjas arborizadas y prados a lo largo de las vías (Fig. 3).

En el conjunto residencial, tal como fue ejecutado, pueden distinguirse dos bandas de viviendas que enfrentan vías ya existentes en la década de 1950. Una primera banda, que corre paralela a la Avenida Manuel Bulnes, constituida exclusivamente por viviendas agrupadas de forma pareada. Mientras que una segunda banda se desarrolla en paralelo a la calle Enrique Abello y se encuentra formada por viviendas agrupadas de manera pareada y aislada. Hacia el interior de la Población Explotadora, pueden reconocerse tanto las viviendas que enfrentan las calles Benjamín Dibasson, Juan Yáñez y Capitán Trizano, como 


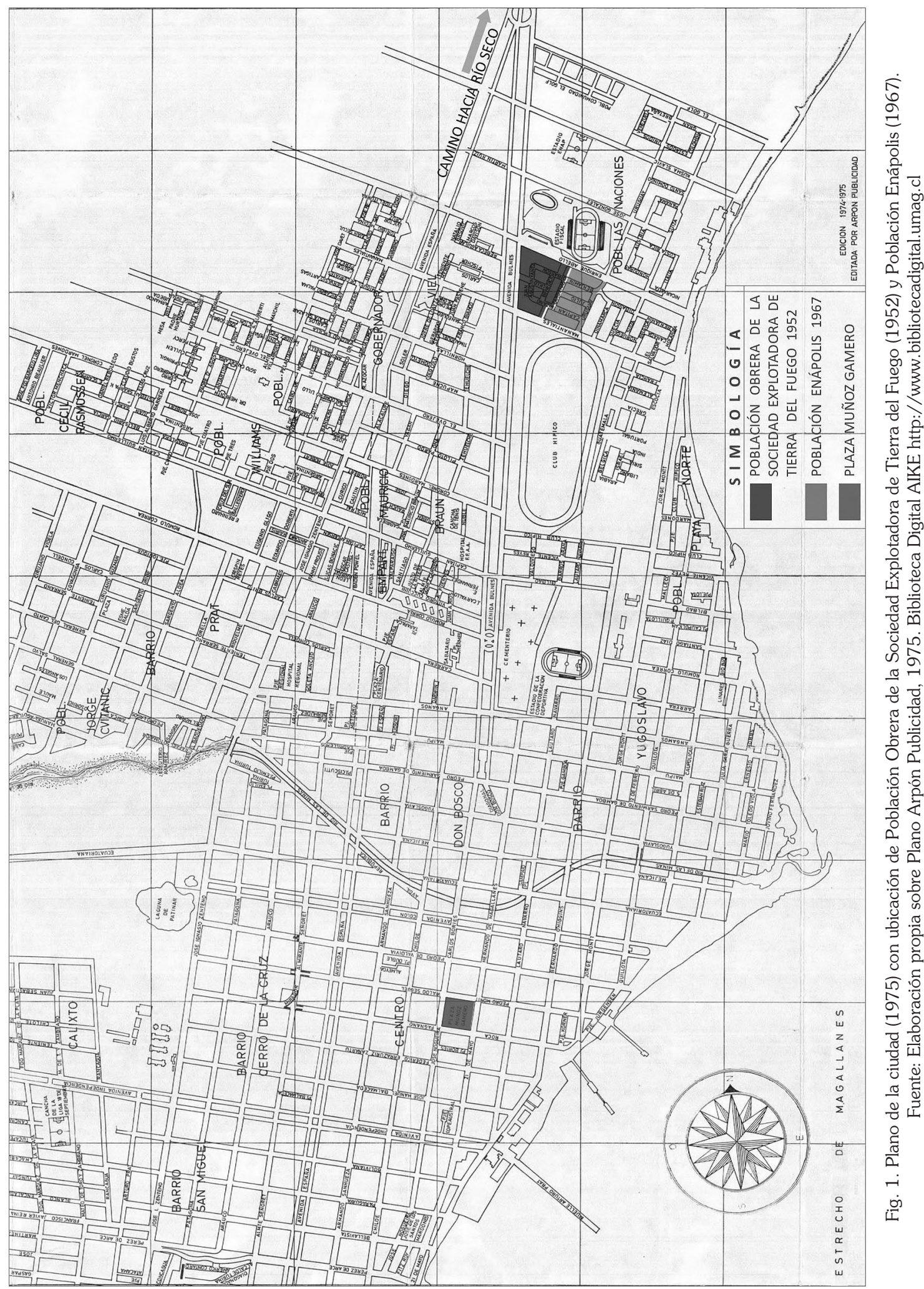




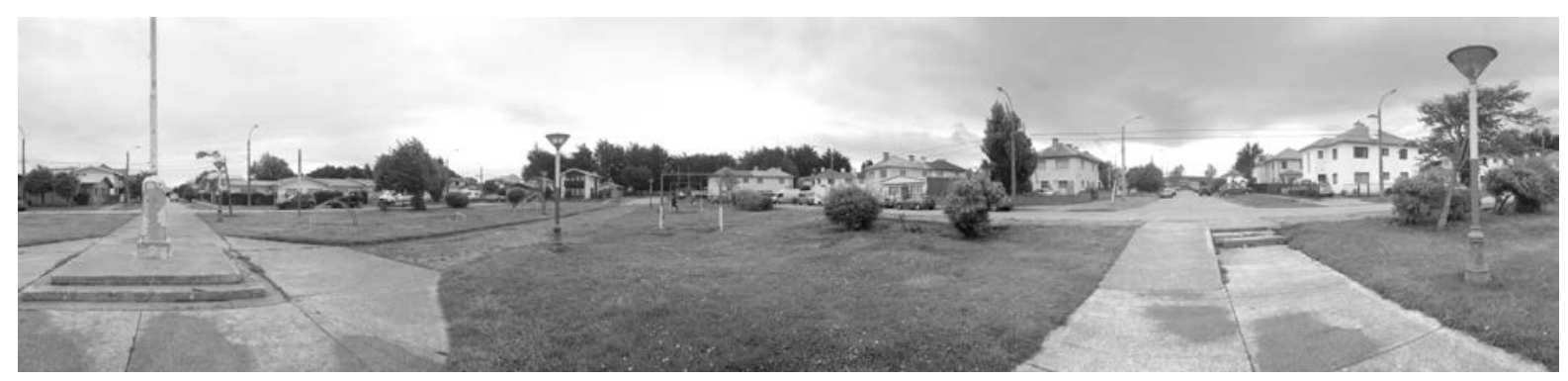

Fig. 2. Imagen panorámica actual Plaza Tierra del Fuego, 2017. Fuente: Daniela Ambrosetti Garrido.

aquellas implantadas en las dos manzanas que enfrentan la Plaza Tierra del Fuego, también agrupadas en un sistema pareado y aislado.

Se trata de un conjunto residencial en baja densidad, formado por dos modelos de viviendas de dos niveles designados en el Expediente de la DOM como el Tipo A (Fig. 4), del que se ejecutaron 6 unidades, y el Tipo B (Fig. 5), del que se ejecutaron 50 unidades (DOM, 1952). El modelo Tipo A corresponde a una vivienda colectiva, que se desarrolló siempre aislada en su parcela, compuesta por dos unidades habitacionales que se dispusieron en cada una de las dos plantas que la forman y que contaron con accesos independientes en el sitio que ocupan. Cada unidad habitacional consideró una superficie de $77,61 \mathrm{~m}^{2}$, posee un hall de acceso pequeño que distribuye hacia un lavadero y hacia la sala común destinada a servir de estar y comedor, cocina, baño y dos dormitorios casi idénticos de $13 \mathrm{~m}^{2}$ aproximadamente cada uno. El modelo Tipo B correspondió a una vivienda unifamiliar pareada, es decir, una edificación que fue diseñada compartiendo un deslinde común que actúa como eje de simetría para otra edificación de características similares que se ubica en el predio contiguo separada por un muro cortafuego. Cada vivienda contempló una superficie de 95,44 $\mathrm{m}^{2}$ distribuida en dos plantas; la primera planta acogió las funciones comunes del espacio doméstico, un cortaviento que antecede al hall que distribuye hacia la sala común, la cocina, que posee un acceso secundario, la lavandería, el baño y escalera, mientras que la segunda planta consideró tres dormitorios de 7,37 $\mathrm{m}^{2}$ a $12 \mathrm{~m}^{2}$ aproximadamente.

Desde un punto de vista material, ambos modelos presentaron características idénticas; fueron realizados en albañilería reforzada, losa y escaleras de hormigón armado, cubierta de fierro galvanizado, muros y tabiques interiores de bloques de cemento, el piso de madera y de baldosas en recintos húmedos (baño, cocina y lavandería). Sin embargo, desde un punto de vista técnico, presentaron sistemas de calefacción diferenciados. Así, en el modelo Tipo A, un serpentín que al discurrir por el cielo permitía temperar parte de la vivienda; en el modelo Tipo B, un sistema de aire caliente templaba la vivienda a través de dos ductos provenientes de la cocina y la chimenea en el primer nivel con salida a cada uno de los dormitorios del segundo nivel (Ambrosetti et al. 2016, pp. 128-129).

Desde un punto de vista urbano, es interesante notar que todos los modelos Tipo A se implantaron en sitios esquina, cuyas superficies variaron entre $251 \mathrm{~m}^{2}$ y $289 \mathrm{~m}^{2}$ y que en la práctica liberaron dos secciones exteriores para cada una de las unidades habitacionales, de 85 $\mathrm{m}^{2}$ y de $105 \mathrm{~m}^{2}$, que cumplían las funciones de jardín de la vivienda hacia el frente público y patio interior. En contraste, los modelos Tipo B quedaron implantados tanto en sitios esquina como entre medianeros, sin presentar en uno u otro caso variaciones, se trató además de predios de $245 \mathrm{~m}^{2}$ aproximadamente, que permitieron disponer de un espacio exterior de al menos $200 \mathrm{~m}^{2}$ distribuidos en un jardín exterior que antecede la edificación y un patio interior o trasero de grandes dimensiones desde donde también podía accederse a la vivienda.

\section{Metodología de trabajo utilizada}

La información para el estudio fue recopilada a través de una revisión de fuentes documentales, compuestas por archivos y planos relativos a la historia de la empresa y su injerencia en la región magallánica, y de la historia y arquitectura de la 


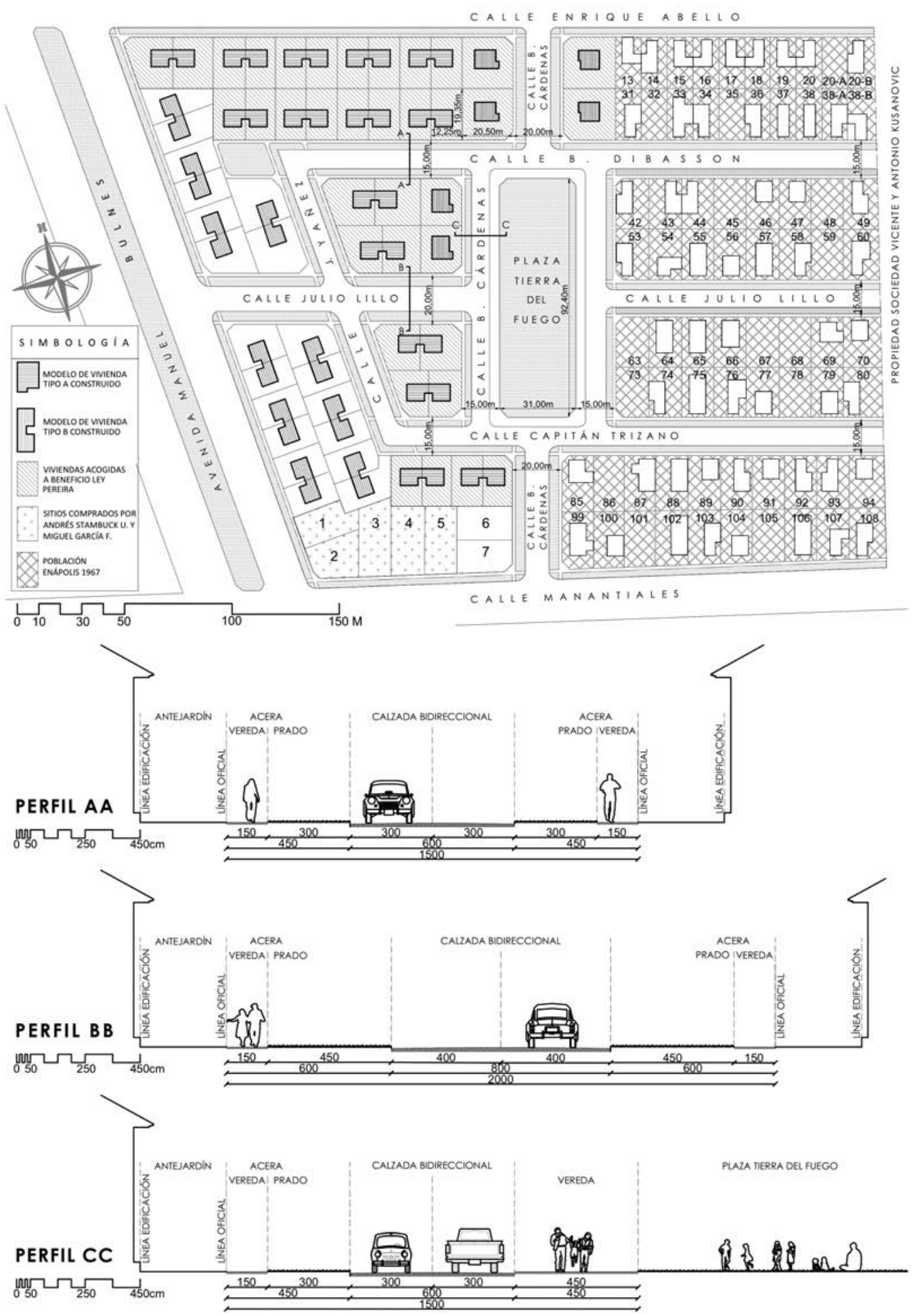

Fig. 3. Plano de loteo y perfiles de vías Población Obrera de la Sociedad Explotadora en 1966. Fuente: Dibujo Daniela Ambrosetti G. en base a Expediente N²00 Población Explotadora, DOM I. Municipalidad de Punta Arenas, 1951. 


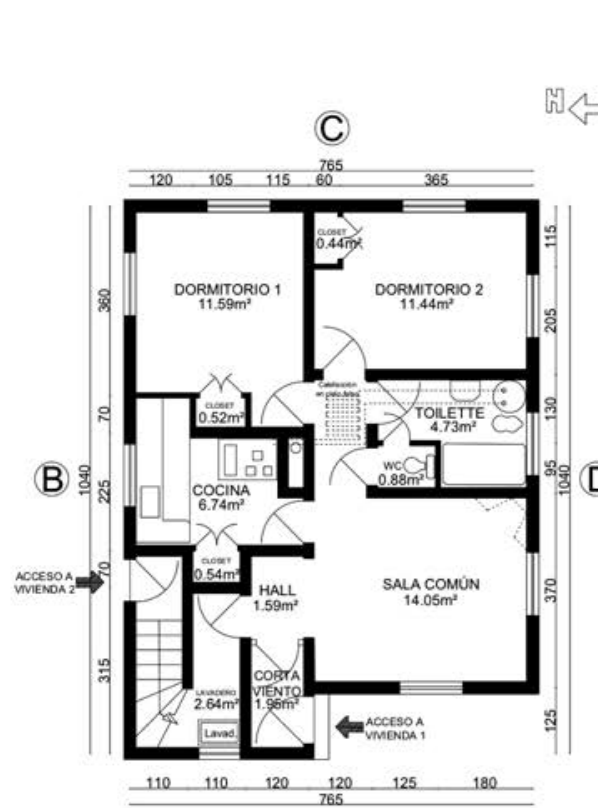

(A)

PLANTA PRIMER PISO VIVIENDA 1
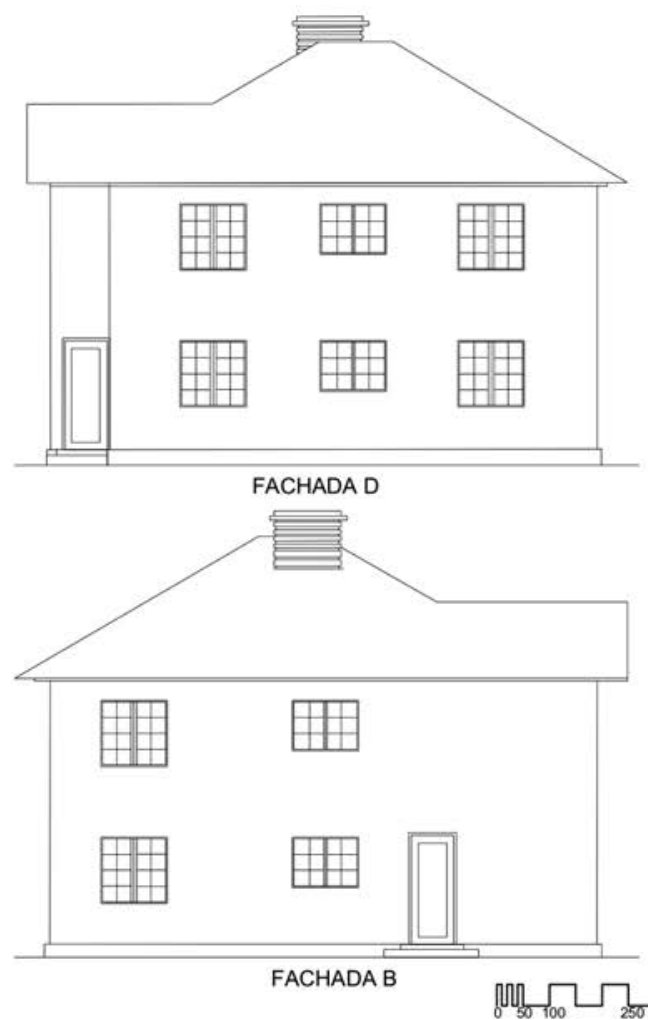

(D) (B) 융

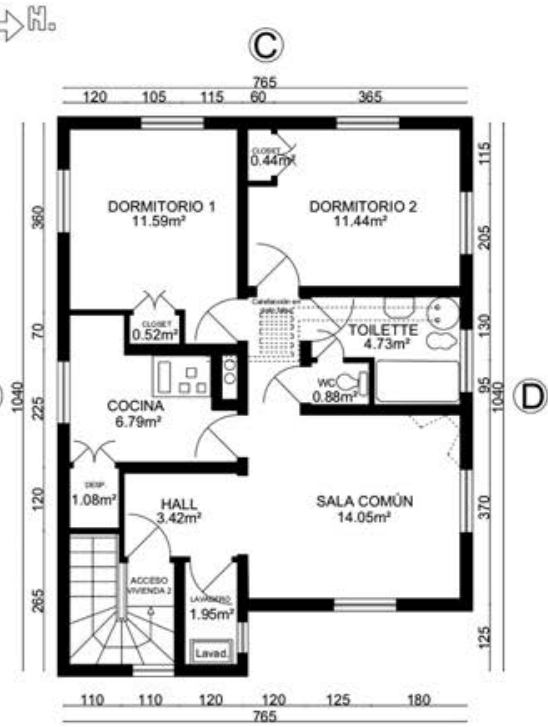

(A)

PLANTA SEGUNDO PISO VIVIENDA 2
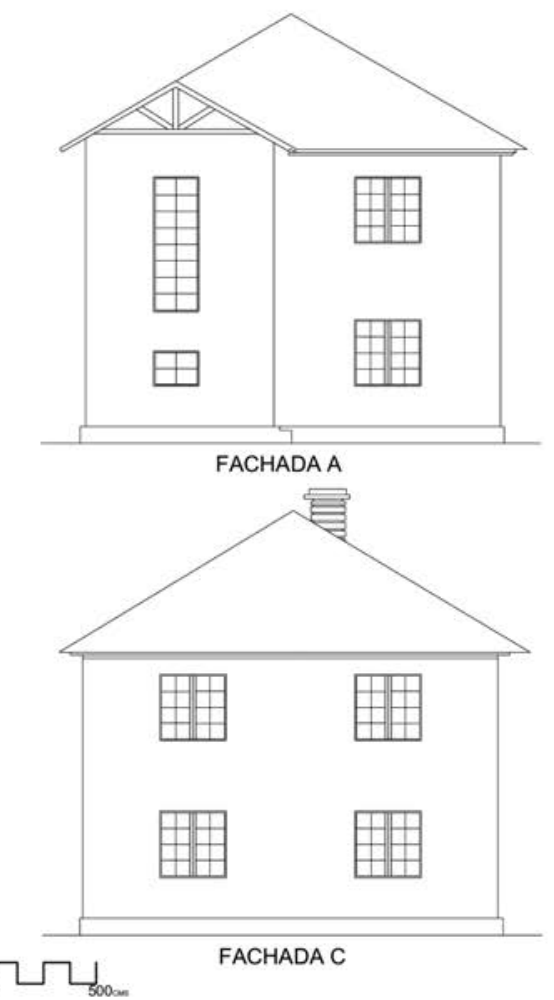

Fig. 4. Planimetría de planta y fachadas de arquitectura vivienda Tipo A (aislada).

Fuente: Dibujo Daniela Ambrosetti G. sobre original de Expediente N²00 Población Explotadora, DOM I. Municipalidad de Punta Arenas, 1951. 
Población Explotadora construida en Punta Arenas en la década de 1950. Además, en paralelo, se trabajó en la recopilación de fuentes orales, a través de la realización de entrevistas en profundidad, más la ejecución de un taller de trabajo -utilizando la técnica del mapeo colectivo $^{2}$, con vecinos $y$ ex vecinos del conjunto residencial. Todas estas estrategias de recolección de información fueron complementándose de forma simultánea, permitiendo un mejor análisis posterior de los datos.

Por un lado, se obtuvo documentación técnica desde la Dirección de Obras Municipales de la Ilustre Municipalidad de Punta Arenas, primordialmente antecedentes planimétricos originales que, junto a otros documentos certificados, entregaron un panorama general de la concepción urbana del conjunto residencial realizado para obreros. Paralelamente, se estudió la prensa de la época, tanto La Prensa Austral como El Magallanes, para conocer el contexto y precisar fechas de aquellos hitos que marcaron su desarrollo, además de la obtención de ciertas imágenes del proceso de construcción $e$ inauguración. También se recurrió al archivo del Instituto de la Patagonia de la Universidad de Magallanes, donde se revisaron tanto el registro de las Actas de Sesiones Municipales de la década de 1950, como aquellos planos históricos de la ciudad de Punta Arenas, que permitieron respaldar los procesos de discusión en torno a la vivienda obrera en la ciudad y estudiar el contexto en la que fue erigida. El conocimiento relativo a los procesos de compra y venta de terrenos, de parcelación del suelo urbano, se obtuvo a través de las pesquisas realizadas en documentación de bienes raíces disponible en el Archivo Nacional de Chile, en particular el Archivo Nacional de la Administración (ARNAD). Finalmente, a través del trabajo en terreno, se logró distinguir de la información original relevada, aquello que pudo

2 Para mayor información respecto a la técnica de mapeo colectivo y herramientas de código abierto consultar: www.iconoclasistas.net

3 La sede vecinal corresponde a lo que originalmente fuera una vivienda del conjunto residencial. La Población Explotadora pertenece, junto con otros conjuntos habitacionales, a la unidad vecinal General Bulnes.

4 En relación a este punto, los investigadores se han guiado éticamente por las Pautas éticas internacionales para la materializarse, permitiendo ajustar y ahondar en las interpretaciones finales de su expresión espacial.

Por su parte, las entrevistas fueron desarrolladas en etapas. Una primera en enero de 2017 y la segunda en mayo del mismo año. El taller fue realizado el día sábado 27 de mayo, en la actual sede vecinal de la Población Explotadora, junto a un grupo de vecinos interesados en hablar sobre la memoria del conjunto residencial ${ }^{3}$. Al respecto, el objetivodeeste ejerciciofue relevar elorigen colectivo en la construcción de recuerdos, asumiéndolos como resultado de procesos de interacción entre vecinos y ex vecinos de la Población ${ }^{4}$. El énfasis radicó en dimensionar hitos comunes consolidados como grupales y que diferencian de la sociedad global, ya más fragmentada (Halbwachs, 2004). Vista así, la memoria colectiva constituye un proceso de selección, interpretación y transmisión de ciertas representaciones del pasado producidas y conservadas específicamente para y desde el punto de vista de un grupo social determinado. Por lo tanto, el conjunto de significados producidos adquiere importancia en el contexto donde se gesta, y para aquel colectivo particular, reafirmándolo en su existencia; dejando de lado a personas de otras colectividades que no encuentran en esos relatos recuerdos coincidentes.

Complementando este trabajo, tanto en las entrevistas como en el taller de memoria, se trabajó en base a fotografías de época que los propios habitantes y ex habitantes de la Población Explotadora poseían, de manera de gatillar recuerdos y abordar desde las imágenes ciertos énfasis de carácter simbólico que permitían contrastar el pasado con el presente. Desde esta dinámica se exploró en la relación que puede establecerse entre la construcción de la memoria social, en tanto fenómeno que teje y entrecruza sensaciones del presente con imágenes del pasado, y los espacios construidos, en su condición de lugares practicados a través de usos, miradas o palabras.

investigación relacionada con la salud con seres humanos (OPS \& CIOMS, 2016) y en consecuencia han estimado que el trabajo de campo involucraba conocer y manipular datos sensibles de la población objeto de estudio. En ese marco, a los y las entrevistados/as se les garantizó no solo la confidencialidad y anonimato respecto a lo expresado verbalmente, sino también se les dieron garantías de protección al uso y manejo de la información entregada. 

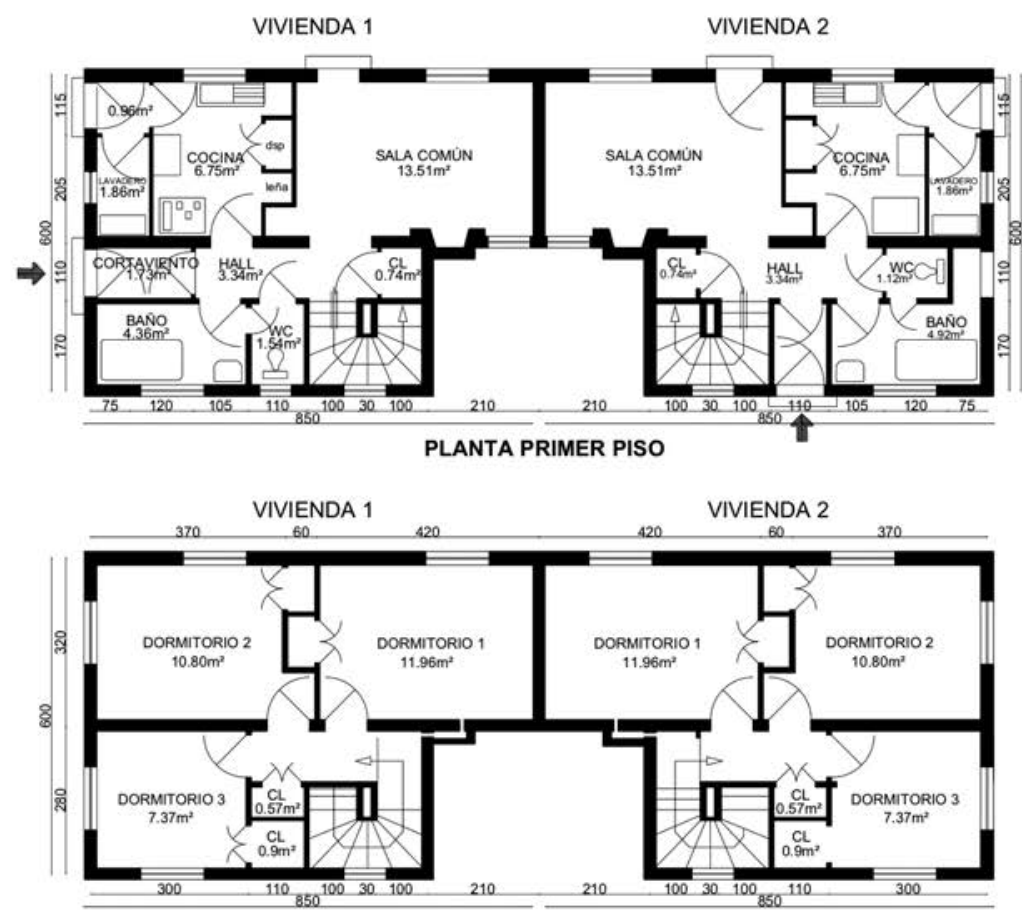

PLANTA SEGUNDO PISO

గొ几
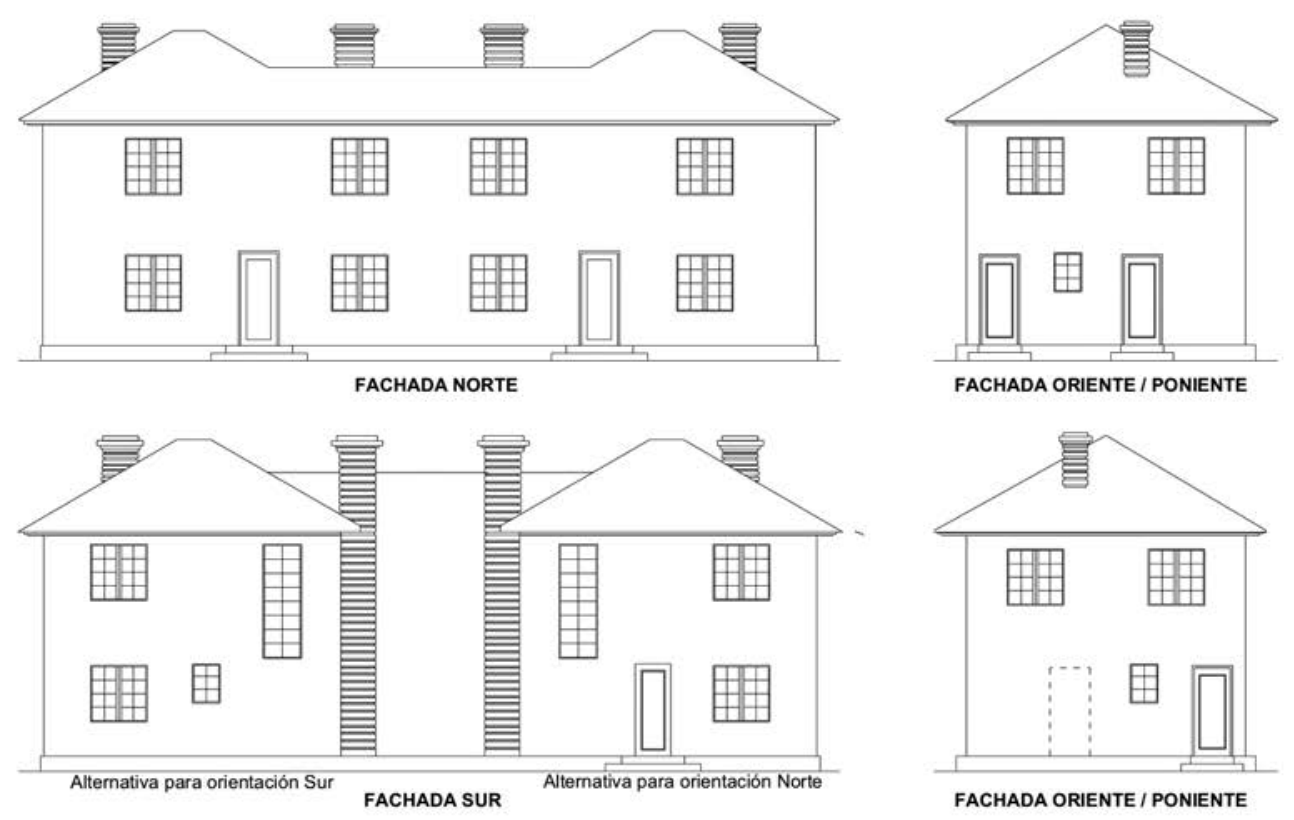

\section{에유}

Fig. 5. Planimetría de planta y fachadas de arquitectura vivienda Tipo B (pareada).

Fuente: Dibujo Daniela Ambrosetti G. sobre original de Expediente N²00 Población Explotadora, DOM I. Municipalidad de Punta Arenas, 1951. 


\section{TEJIDO SOCIAL EN LA POBLACIÓN SOCIEDAD EXPLOTADORA DE TIERRA DEL FUEGO}

Las huellas del paternalismo industrial en la memoria colectiva de la Población

El tejido social que emerge en los sectores residenciales asociados a las áreas industriales va intimamente relacionado con la conformación del espacio urbano. En el caso de la Población de la Sociedad Explotadora de Tierra del Fuego la empresa decidió construir, en la periferia de lo que era la ciudad de Punta Arenas en aquellos años, un conjunto residencial en arriendo, destinado inicialmente a obreros y sus familias (Ambrosetti et al. 2016). Ello significó que toda la configuración urbano-arquitectónica de la emergente Población Explotadora quedó bajo los designios de la industria proveedora, cuya propuesta de diseño urbano y construcción de viviendas se atuvo a la explícita intención de otorgarle "...mejores condiciones de vida al obrero y su familia, y contribuyendo así a levantar el nivel de vida del obrero de la zona" (DOM, 1952).

En términos de los habitantes del conjunto residencial, esta situación se interpreta desde la condición benefactora de la empresa y su cualidad protectora.

La necesidad de la empresa era ver cómo los que tenían trabajando en sus Estancias..., porque no solamente había gente acá en el continente, sino que también en Tierra del Fuego..., entonces seleccionaba a aquellos que definitivamente necesitaban con más urgencia donde vivir y les entregaban la casa habitación en Punta Arenas (Participante 1, Taller Participativo 27/5/2017).

Lo que yo sé es que cuando nací, a mis papás les prometieron que cuando se desocupara una casa nos íbamos a ir a vivir a la Población en Punta Arenas... Viviamos en ese tiempo en Oazy Harbour, como a $100 \mathrm{~km}$ de la ciudad... y era un privilegio esto (Entrevistado 1, 26/5/2017).
Siguiendo estas palabras, es posible establecer que, en su modelación, la Población Explotadora respondió al criterio paternalista de fijar a familias de trabajadores de la empresa en la ciudad para que actuara como proveedor de ciertos servicios, con el fin de dar estabilidad al núcleo social básico de reproducción social, cual es la familia. Pero se reconoce que se hizo asegurando viviendas destinadas a obreros, de gran calidad para la época.

Las casas de la Ganadera estaban muy, muy bien hechas. De partida, eran todas de cemento y bien gruesas también. Pero, además, por dentro tenían unos conductos que subian con el aire caliente y se dispersaba a través de las paredes. Si uno tocaba las paredes, estaban todas tibias. Tenían un fogón en el sector del living que se prendía por las tardes y calentaban toda la casa, con leña y carbón se calentaba. Y después estaba la otra chimenea en la cocina que tenía otros dos conductos que iban a través de toda la casa también. Así eran las casas, si eran hechas por los ingleses. En el baño habia un estanque que estaba en altura que hacía circular el agua por gravedad (Entrevistado 1, 26/5/2017).

Desde el punto de vista de la empresa, la idea parecía apuntar a revestir de sensibilidad social la noción de que controlando ciertos elementos de la vida del trabajador era posible incidir en su productividad. Desde la perspectiva de los trabajadores, se trató de la oportunidad de acceder a un beneficio difícil de conseguir por cuenta propia. Esta simbiosis permitía pasar por alto el hecho de que los trabajos en las faenas de las Estancias duraban 3, 6 o incluso 12 meses, relegando al jefe de familia a ser una figura nominal antes que presencial (...cuando yo ya cumplí dos años, le dieron casa a mi papá. Eso fue el año '59. Se vino mi mamá conmigo, mi papá se quedó trabajando. Bajaba cada tres meses. Eso pasaba en casi todas las casas Entrevistado 1, 26/5/2017), y de que la propiedad de las viviendas siempre permaneció en manos de la empresa, quien podía otorgarlas, o bien quitarlas, según su criterio. 
Se reconoce aquí una expresión de paternalismo industrial, entendido éste como aquel conjunto de mecanismos de control empresarial destinados a cubrir una serie de demandas sociales de los trabajadores. A saber: vivienda, salud, educación de los infantes, entretención y otros aspectos ligados a la sociabilidad. Destinados básicamente a influir en el interior de los conjuntos residenciales diseñados para la fijación de los trabajadores, con el fin de disponer de mano de obra segura y altamente adiestrada (Godoy, 2015, p. 119). En términos teóricos, esta lógica persigue regular y disciplinar a los operarios, controlando los espacios y tiempos del trabajo, pero también los del no-trabajo (Sierra Álvarez, 1990, p. 77; Godoy, 2015, p. 123). Y uno de sus aspectos fundamentales es precisamente que los trabajadores no sientan este principio regulatorio como una imposición, sino que participen de él, sintiéndolo como parte de los beneficios que otorgaría la empresa (Mantecón, 2010).

A partir de aquí es de interés atender al relato de memoria que se reconstruye actualmente en relación a la vida cotidiana pasada en la Población Explotadora, por parte de sus habitantes y ex residentes. Y observar cómo en él se evidencia la internalización, a través de las relaciones sociales, de este principio controlador. Se entiende que, en este proceso, como en todo ejercicio recordatorio, ciertos pasajes son olvidados y otros enfatizados, en este caso específico con el objetivo de reconstruir un pasado vivido colectivamente y que se expresa en forma de hecho social que remite a un grupo, antes que a la sociedad en su conjunto. Ello, porque el objetivo final es enfatizar un sistema de valores compartido particularmente por un grupo determinado frente al conjunto social (Halbwachs, 2004).

En este orden, características urbanísticas o netamente accidentales son incorporadas $e$ interpretadas a partir del valor que ello tuvo para la consolidación del espíritu colectivo de los habitantes de la Población Explotadora, en relación al conjunto de la sociedad, en este caso, el resto de la sociedad de Punta Arenas.

Es que nosotros éramos como los más alejados de la ciudad, éramos los últimos, nosotros éramos la última y la primera Población fuera de... (Participante 5, Taller Participativo 27/5/2017).

No nos sentíamos tan aislados de la ciudad como para decir que viviamos fuera de ella, pero estábamos lejos... (Entrevistado 1, 26/5/2017).

Esta eventualidad habría favorecido el desarrollo de una vida social particular. Conectada con un 'afuera' por temas de abastecimiento, educación y ocio, ello no impidió que se desarrollara un hacia 'adentro' intenso, que puso en estrecha relación al conjunto de núcleos familiares, hasta tal punto que la vida social en el conjunto residencial se desenvolviera 'a puertas abiertas' entre la mayoría del grupo de vecinos, conformándose una vida social intensa y donde se vivía colectivamente.

Vivíamos muy aclanados. No había teléfonos, solo uno, que era el teléfono del chofer del Gerente y él tenía teléfono por si lo necesitaban. Entonces, uno salía a jugar y llegaba la hora de almuerzo y uno almorzaba donde te pillaba el juego, como eran casas abiertas, estaban abiertas para todos. Lo mismo, si días después estabas jugando y te pillaba la hora de once, entrabas a la casa de alguien a tomar la once. Asi era (Entrevistado 1, 26/5/2017).

Yo creo que el hecho de estar aislado hizo mucho para tener esa vida que tuvimos alli (Entrevistada 3, 30/5/2017).

Estos elementos parecen configurar una idea de conjunto residencial inserto en la ciudad que responde a ese espacio que, en términos de Mongin (2006), se define por la articulación del adentro -el refugio-, con el afuera -la urbanidad-, y en donde lo importante acaba por ser la relación que se establece entre ambos, antes que cada uno por separado.

Entonces, hubo factores intencionados desde el diseño urbanístico y la idea de construir una Población Explotadora para los trabajadores y sus familias como estrategia de fijación y regulación por parte de la empresa, pero también parece ser que la experiencia vivida amplió el espectro de intencionalidades de la industria y no solo ofreció "mejores condiciones de vida al obrero y 
su familia”, sino que permitió el desarrollo de una experiencia social que hoy es guardada como un recuerdo irrepetible de una época.

Si seguimos a Mantecón (2010), estaríamos aquí frente a la expresión de un paternalismo industrial que reconoce formas de disciplinamiento social constituidas y proyectadas desde ámbitos enraizados en esferas no elitistas, institucionales $\mathrm{u}$ oficiales de la sociedad. Operando en cambio la fuerza de la asistencia social, y su concentración en los ámbitos de la familia, en tanto principio posible de la idea de comunidad. Pero todo ello no en tanto conjunto de estructuras rígidas e infranqueables. Porque nunca se ha llegado a lograr una sociedad absolutamente disciplinada, reducida a una obediencia acrítica y que responda de forma automática a los valores proyectados desde arriba. Tampoco desde abajo ha sido todo consensos. Sino más bien el resultado de presiones, resistencia y valores variables, lo que también iría acompañado de capacidad creativa para generar reglas de convivencia gestadas desde la propia experiencia cotidiana.

De esta manera, entendemos que el disciplinamiento social exige adhesión, consenso, aceptación, pero también, y por sobre todas las cosas, participación. Y esta última, en el caso de la Población Explotadora, operó desde una lógica social que construyó un marco de cotidianeidad que la solventaba, al tiempo que la reproducía. Se participaba de una forma de disciplinamiento, pero porque se participaba de una vida social vecinal intensa.

\section{Vida cotidiana como valor social compartido}

Dos hitos, operando simultáneamente, permiten dar testimonio de la particular expresión de paternalismo industrial que combinaba disciplinamiento con participación en la Población Explotadora.

Por un lado, a sabiendas de que la población masculina era mayormente itinerante ${ }^{5}$ (pasaba de 3 a 6 meses en las Estancias, o incluso haciendo el 'año redondo' como

5 Los testimonios indican que, si bien al principio las viviendas fueron entregadas básicamente para los trabajadores de las Estancias Oazy Harbour y Punta Delgada, en algún momento la Población fue dividida en mitades: una para denominaban a la totalidad del año), la presencia paternal de la empresa se acentuaba, dada la importancia adquirida por las asistentes sociales y el administrador de la Población Explotadora, contratados por la empresa. Ambos eran responsables de la supervisión del estado de las casas y del arreglo de los desperfectos, además de evaluar a sus residentes según criterios preestablecidos de comportamiento y necesidad detectados.

Mi papá, él estaba encargado de recorrer la Población todos los días. Recorrer, visitar a las personas, entregar la correspondencia que mandaban los esposos de las Estancias (Entrevistada 2, 29/5/2017).

Me acuerdo una vez que hubo un terremoto blanco y se cayeron las canaletas con la nieve que cayó. Y todo eso lo tenía que ver mi papá [el administrador], que viniera la gente a hacer el trabajo, los materiales, todo. Porque hay que ver que las señoras pasaban 3 meses solas, porque los maridos estaban lejos, en las esquilas. Se trabajaba por 3 meses, otros por seis, y había quienes hacían el "año redondo", el año completo afuera. Y mi papá [el administrador], con la asistente social, recorrian las casas preguntando las necesidades en cada una. Y las calificaban como tenían las casas; unas tenían 'sobresaliente', cosas así (Entrevistada 2, 29/5/2017).

A través de otras instancias, también la empresa resolvía el abastecimiento de los residentes. Por ejemplo, ofrecer a los pobladores dos veces por semana carne a menor precio. O permitiéndoles comprar víveres en las bodegas de la empresa destinadas a las Estancias, donde según testimonio de los vecinos era posible acceder y disponer de "todo lo que era tarro" (sic) a un costo más bajo. Además, en el recuerdo colectivo está muy presente el negocio de Manuel Ruiz, único local comercial en las cercanías de la Población Explotadora y

vivienda de trabajadores, la otra para administrativos de las oficinas que la Sociedad Explotadora abrió en la ciudad de Punta Arenas. 
en el que se podía comprar a cuenta. Ninguno de estos establecimientos comerciales estaba ubicado al interior del conjunto residencial, sino en edificaciones que existían previamente en la ciudad, por cuanto en el diseño original de la población no fue considerado este tipo de equipamiento.

El segundo hito a destacar muestra cómo los patrones de sociabilidad desarrollados en la Población Explotadora lograron establecer una armonía a partir de las relaciones informales que comenzaron a definirse y reforzarse bajo un clima de cierta adhesión a valores de buena vecindad, más allá de las largas ausencias de los hombres en las faenas laborales. Y quienes constituyeron un núcleo fundamental para el incremento de este tipo de sociabilidad vecinal fueron los niños y adolescentes, teniendo a la plaza como lugar de excelencia para la concreción de este tipo de vínculo social.

Aqui había mucha convivencia, se compartía. Si en las tardes la plaza estaba llena, pero llena de niños (Participante 2, Taller Participativo 27/5/2017).

La base de la amistad que surgió entre todos nosotros fue la plaza. Esa plaza era muy especial en su época... La plaza era el lugar de encuentro en la Población... todo giraba en torno a la plaza (Entrevistada 3, 30/5/2017).

Después del colegio nos juntábamos todos acá, a jugar a la pelota, a la mancha, tocar timbres, a quebrar vidrios... (Participante 5, Taller Participativo 27/5/2017).

Si bien en la planimetría original, la plaza ocuparía un lugar central en la estructura urbana de la Población Explotadora, este plan no se cumplió y los terrenos ubicados en dirección al mar finalmente fueron vendidos. Así, la plaza no acabó en el centro geométrico de la Población Explotadora (Fig. 6), pero su centralidad acabó por ser simbólica, ya que era el lugar de referencia y donde se recuerda que siempre había niños jugando. Esta situación es llamativa si consideramos que las mismas referencias indican que todo alrededor de la Población era pampa, o sea, sitios eriazos con amplios espacios para estar y jugar. Pero la plaza logró conformarse como un lugar de encuentro y reunión, un lugar apropiado por un conjunto de individuos a través de usos que lo volvieron único.

Esta característica podría llevar a pensar que la memoria colectiva de la Población Explotadora está sujeta a los recuerdos de infancia de un grupo de niños que vivió una experiencia única de camaradería y sentido de unión. Si bien tales características sí se encuentran presentes, también es un hecho que la memoria almacena imágenes que exceden la etapa de la niñez e involucran a un conjunto de familias que se congregaban al amparo de la buena vecindad, la que iba más allá
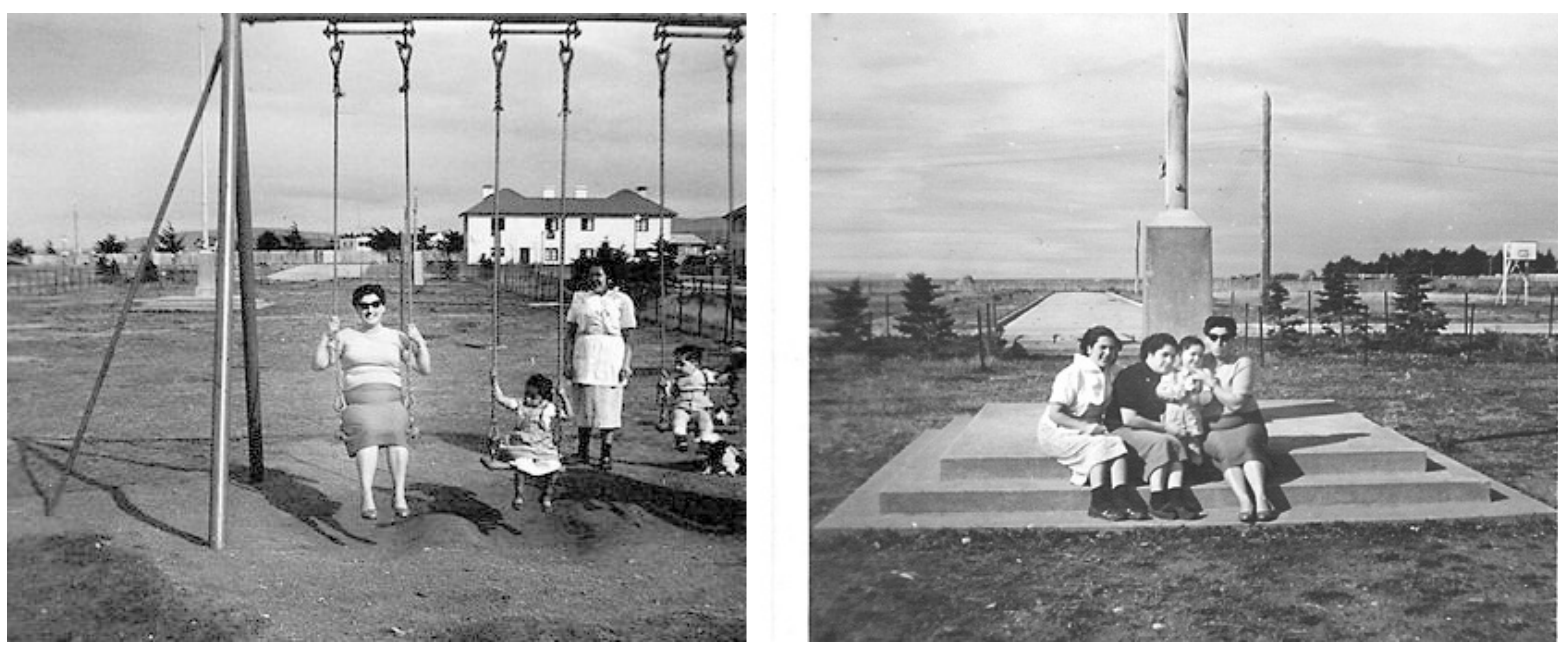

Fig. 6. Plaza Tierra del Fuego, 1959

Fuente: Sergio Maldonado Haro. 
de posibles diferencias. Por ejemplo, cuando la Sociedad Explotadora instauró una sectorización que determinó residencias de empleados y obreros, abriendo la posibilidad de explicitar en los usos del espacio público diferencias sociales.

Pero la distinción, real en la distribución de las casas, al parecer no logró ser incidente, en gran medida porque una serie de actividades de orden ritual logró imponer una lógica de congregación colectiva, por sobre el interés por atomizar la vida familiar.

No se notaba, por lo menos entre los niños, la división entre empleados $y$ trabajadores. Tampoco se veía entre los adultos. Sí había personas que definitivamente no se juntaban con el resto, pero no porque tuvieran mala onda o algo así, sino que como que no existían no más (Participante 2, Taller Participativo 27/5/2017).

La esfera ritual donde aquellas cualidades de sociabilidad se desplegaban abarcaba las festividades, celebraciones y otras actividades que permitían reunirse a la gente. Entiéndase fiestas navideñas, celebraciones de fiestas patrias, año nuevo y otros. Particularmente importante parece haber sido el ritual navideño, un hito donde la congregación familiar nuclear dejaba espacio a la reunión del colectivo.

Y lo que era navidad o año nuevo, se formaban los grupos de los adultos, de los jóvenes, los medianos y los chicos, y se recorría casa a casa, saludando y todo eso. Y en todas las casas nos esperaban, se esperaba que se pasara. Además, la navidad se hacía con un viejo pascuero que llegaba en un camión con regalos para todos. $Y$ eran buenos regalos, no eran cualquier cosa (Participante 2, Taller Participativo 27/5/2017).

Para las navidades todos recibíamos el mismo regalo. Yo la que más me acuerdo es una vez en que a los chicos les llegó una bicicleta y a las chicas un reloj pulsera. Me acuerdo porque eran como muy modernas para su época, eran bonitas, Bianchi me acuerdo. Y todos tenían la misma, pero de distinto color (Entrevistada 3, 30/5/2017).

Muy importante en todas estas dinámicas acabó por ser la sede social, que nació utilizando una vivienda desocupada que fue transformada en lugar de reunión colectivo. Ubicada frente a la plaza, acogió una multiplicidad de actividades de índole congregativa, que iban desde misas, juegos de mesa entre amigos, hasta cumpleaños; además de ser sede del club deportivo y de la Junta de Vecinos, entre otros (Fig. 7).

Se celebraban los cumpleaños, se hacian fiestas en la sede, se elegía reina, el club deportivo. Incluso un tiempo hubo una batalla, porque nosotros los de la iglesia teníamos que hacer misa todos los domingos a las 9 de la mañana, pero los del club venían por la noche y dejaban todo sucio. Entonces nosotros teníamos que venir a limpiar. $Y$ el padre nos decía 'no le hagamos el gusto, sigamos adelante'. Después, con el tiempo ya no se hizo más misa en la sede, ya había una iglesia cerca (Entrevistada 2, 29/5/2017).

Este tipo de asociatividades vecinales son propias y promocionadas por las lógicas paternalistas, como forma de alejar teóricamente de otras actividades ligadas al 'vicio' o a la organización reivindicativa. En este contexto, como suele suceder en muchos casos, el Club Deportivo estaba en lo alto de las prioridades. Además, la Sociedad Explotadora proveyó de canchas de básquetbol y fútbol, allí donde posteriormente se ubicó la Población Enápolis, a mediados de la década de 1960. Con posterioridad, las actividades ya se realizaban en otras dependencias, como en el mismo Estadio Municipal que se construyó en el costado norte de la Población Explotadora (Fig. 8).

Las huellas del paternalismo:

la memoria enfrentada al presente

La temporalidad de la época de buena vecindad es un dato impreciso en la memoria de los actuales vecinos. El tiempo en que la experiencia de vida en la Población Explotadora aconteció rodeada de 

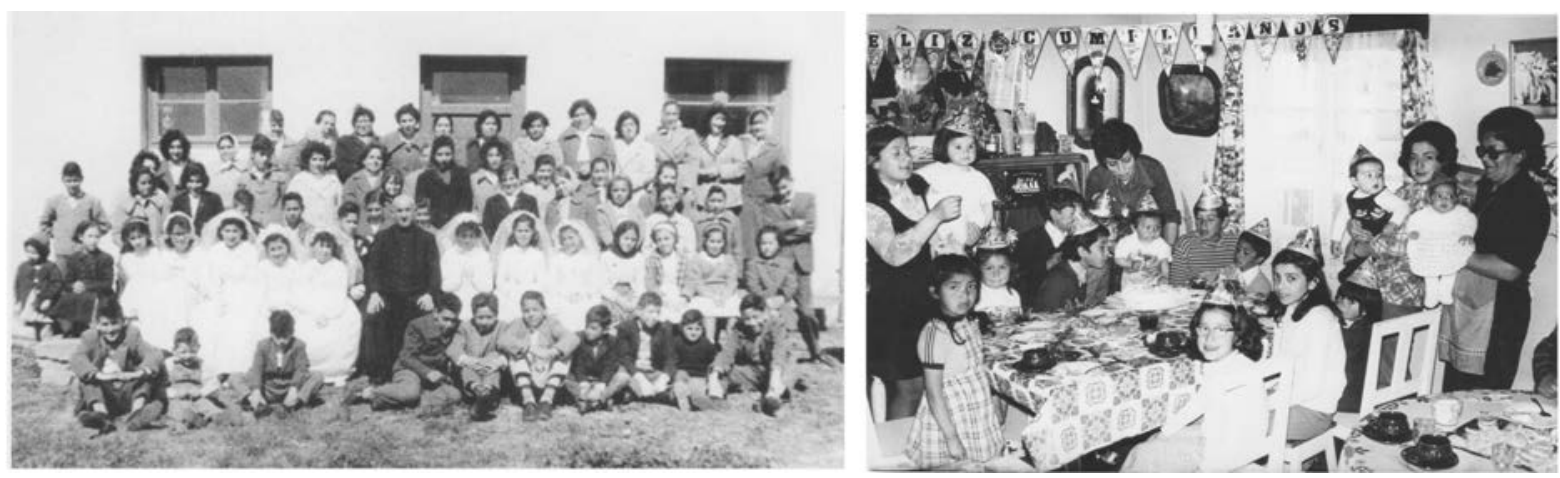

Fig. 7. Confirmación de niños y niñas de la Población (ca.1965) y Cumpleaños familia Mansilla-Alarcón 1976 (der.). Fuentes: Carlos Aro Pérez y Margarita Alarcón Flores.

buenos recuerdos y con gran actividad interna no se ciñe a fechas, sino más bien a momentos, anécdotas, recuerdos, experiencias comunes, representaciones de sociabilidad. Si fuese necesario proponer un rango temporal, iría desde finales de la década de 1950 hasta mediados de la década de 1970.

Sí se observa un hito tangible que marca un declive: el momento en que la Sociedad Explotadora decide vender las viviendas. Acontecimiento que precedió a la disolución de la empresa por efecto de las transformaciones de la tenencia de suelo derivadas de la Reforma Agraria, entre mediados de la década de 1960 e inicios de la década de 1970. Aunque se buscó otorgar preferencia idealmente a quienes residían en ellas, por capacidad económica, fueron pocos los obreros que pudieron comprar, mientras que entre los empleados hubo mayores probabilidades. Los tratos se realizaron preferentemente a través de la Asociación de Ahorro y Préstamo Patagonia y, bajo esa lógica, la adjudicación final de las viviendas quedó determinada por factores diversos, entre ellos las capacidades de ahorro y endeudamiento de los grupos familiares. Entre quienes perseveraron en el intento por comprar sus casas, hubo muchos que con el tiempo debieron irse, imposibilitados de poder pagar su valor.

Es este el inicio de una transformación paulatina, que se dio de forma casi imperceptible, pero sostenida, y que fue modificando los rostros que componían la Población Explotadora. Y con el cambio de personas, también vendría el cambio de la forma de vivir el lugar.

Los nuevos dueños [de la vivienda] son desconocidos, compraron la casa. Ellos no saben mucho, no añoran lo que nosotros vivimos, porque su vida fue distinta (Participante 5, Taller Participativo 27/5/2017).
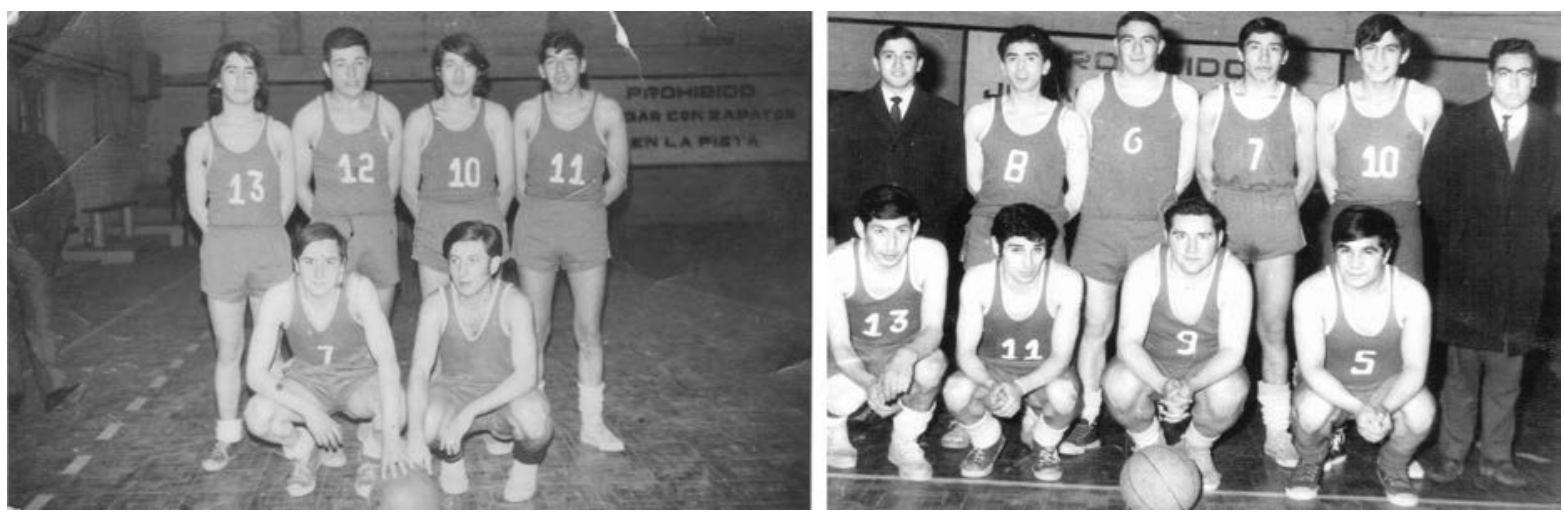

Fig. 8. Equipo de Básquetbol, Club Deportivo Explotadora (1967 y 1964).

Fuentes: Carlos Aro Pérez y Tito Romero. 
Consecuencia de este proceso es esa necesidad que emerge de recordar aquello que se va diluyendo. Un hito que estuvo marcado también por la absorción de la Población Explotadora por el resto de la ciudad en su crecimiento llevó a que cobrara otro valor la conservación del recuerdo, aunque fuera de forma no tangible, a través de la memoria.

Nosotros, cuando ahora nos juntamos, añoramos las vivencias de esa época. Porque era otra vida; no había maldad, las casas abiertas. Ahora uno va a la Población y es otra cosa, ya no es lo mismo (Entrevistado 1, 26/5/2017).

Esta noción del presente distinto a lo que fue acaba por constituir un hito que refuerza el pasado a través de su idealización. Los fuertes lazos de vecindad, el libre esparcimiento y la familiaridad en el uso de los espacios del conjunto residencial, marcan una distancia con el tiempo actual. Cuestión que viene a ser reforzada por las redes sociales y el "Grupo del Recuerdo", asociación informal que permite no solo recordar, sino que además confirmar la vigencia que logra tener el pasado en el presente.

Ahora han cambiado los tiempos, ya no existen las personas que en su mayoría quedaron allí...Uno sabe todo esto, porque uno está siempre conectado. Hasta tenemos una página en Facebook y ahí uno se va enterando de las cosas... y estamos todos conectados (Entrevistado 1, 26/5/2017).

El sentimiento de solidaridad vecinal, junto a la imagen de la plaza como lugar intensamente ocupado; o la noción de 'puertas abiertas' que muchas de las casas habrían tenido para un amplio espectro de población, junto a los rituales de buena vecindad vividos, se erige de algún modo en contraste con el presente. No tanto por los cambios urbanos o arquitectónicos acaecidos, sino que también por las transformaciones advertidas por los propios vecinos y ex vecinos en el uso y apropiación del espacio, las relaciones sociales emergidas a partir de ello, y las personas implicadas en estos procesos.
Y asimismo es como se construye la idea de que los cambios acaecidos en la dinámica propia de la vida social vuelven impensable la posibilidad de que pueda repetirse la experiencia pasada, ya sea en las generaciones más jóvenes, como en los mismos vecinos que van quedando. La Población Explotadora emerge como un conjunto más, absorbida por la ciudad y únicamente la memoria colectiva permite volver visible un nosotros frente a la globalidad.

Lo que quedó acá fueron muy bonitos recuerdos, para todos los que vivimos acá. Yo intenté que mi hijo, cuando veníamos de visita a ver a mi papá, se incorporara acá con los niños que se veían, pero ya no era lo mismo. Los papás compartían, jugaban pichangas (Entrevistado 1, 26/5/2017).

Hubo una vida muy especial acá. Y a mí me hubiese encantado que mi hijo pudiera haber tenido la misma infancia que yo acá. Por los juegos, por la amistad, por las vivencias de las navidades, de los años nuevos, que se compartía y no había envidias, que ahora no se ve mucho (Entrevistada 3, 30/5/2017).

Si pudiese volver a esa época, yo cuidaría mucho más lo que se vivió, lo que había. De eso conversamos siempre cuando nos juntamos; de lo que vivimos, de lo que hicimos. Quedan los recuerdos de la época no más, nada más eso sí (Entrevistado 1, 26/5/2017).

\section{CONCLUSIONES}

El presente se alojó en el pasado

Se puede decir que el caso de la Población Explotadora es un ejemplo de cómo el urbanismo y la arquitectura se constituyeron en aliados del disciplinamiento social, distribuyendo el espacio y ejerciendo control sobre él a través del diseño, asignación y uso de viviendas y espacios públicos, así como en la estética arquitectónica propuesta. Si la distancia con el centro permitió la conformación de un adentro y un afuera simbólicos para sus habitantes, el trazado urbano interno de la 
Población Explotadora también escenificó en el espacio ciertos valores sociales, con la respectiva plaza y matizada arquitectura de las viviendas.

Pero no obstante la validez de esta condición, igualmente interesante resulta que, sobre esa propuesta urbana y arquitectónica, los habitantes y ex habitantes del conjunto residencial hayan ido construyendo un relato común basado en elementos intangibles, el que otorgó otros significados a esos mismos espacios edificados o urbanizados de acuerdo a principios cercanos al disciplinamiento social. Y estos elementos intangibles permitieron erigir una memoria colectiva, en base a construir homogeneidad en los discursos, ya sea a través de construir recuerdos, como también de crear olvidos que permiten idealizar el pasado.

Esto puede ejemplificarse en las bondades señaladas sobre la Sociedad Explotadora en tanto empresa que otorgaba beneficios a sus trabajadores y familias, al aparecer obviada la propiedad de las residencias, hasta emerger súbitamente como tema cuando la industria dejó de existir y dejó a los residentes sometidos a la dinámica de un mercado inmobiliario del que desconocían en gran medida sus reglas. En los mismos términos puede entenderse como se observaba la injerencia del trabajo en la vida cotidiana. Si ya está dicho que la presencia de la población masculina en la Población era parcial, por efectos del trabajo estacional requerido en las Estancias, ello no significa que no se haya desarrollado un fuerte concepto de idealización familiar tradicional, aunque ello fuese antes una expectativa que una realidad. Y frente a la ausencia esporádica, pero rutinaria, del padre, la empresa asumía el rol de proveedor. Así, la ganadera suplantaba o minimizaba la importancia de las ausencias a partir de ofrecer garantías, comodidades y tranquilidad que permitía precisamente obviarlas, u olvidarlas momentáneamente. Era, en toda su expresión, la cara más visible del rol 'paternalista' de la Sociedad Explotadora de Tierra del Fuego y sus formas de persuasión y disciplinamiento.

Ahora bien, lo interesante es visualizar cómo frente a estos olvidos emergen, en las voces de vecinos y ex vecinos, aquellos elementos positivos característicos de una época que acaba por establecer una nostálgica resignación en el presente. Y cobran vida a través de relatos e imágenes la amplia integración entre los habitantes, los fuertes lazos de amistad vecinal creados, el respeto, la confianza y el conocimiento entre todos, siempre como valores determinantes en la sucesión de las actividades de la vida cotidiana. Podría entenderse esta dinámica como una respuesta a una pauta de comportamiento social receptiva a conductas más o menos estandarizadas, que promoverían relaciones armónicas, en el entendido de que cada quien se comportaría de acuerdo a lo esperable y tolerable para el conjunto (Mantecón, 2010). Y la clave en este proceso sería la incorporación de los propios habitantes en la construcción de su vida social, siempre siguiendo ciertas directrices de orden social con un trasfondo moral, y en donde se concreta un marcado elogio hacia la participación grupal en las actividades cotidianas y la compenetración derivada de la condición de vecinos.

Este último principio, quizá no tan relevado en la literatura especializada sobre el ejercicio del paternalismo en el contexto industrial, en el caso particular de estudio, cobra relevancia al estar en el origen de la posibilidad de construir un discurso integrador y conciliador de la relación empresatrabajadores en una época de vida en la Población. En efecto, la recopilación de memoria oral a través de entrevistas, individuales o grupales, con habitantes y ex habitantes de la Población -junto a los datos recopilados en archivo-, exhiben un marco social que devenía favorable para la integración entre los vecinos, visualizando como positivo el ejercicio de disciplinamiento implícito derivado del actuar de la empresa, pero valorado en tanto dio cabida al desarrollo de una vida social participativa e integradora.

En el fondo, pareciera que disciplina se asocia a organización, y ésta a mancomunión, combinación que daría lugar a una mejor calidad de vida. El paternalismo entonces habría actuado aquí como un esquema flexible y abierto que permitió, entre las rendijas de aquello pauteado por el mundo cotidiano formal, el desarrollo de una vida social rica en experiencias colectivas, la que hoy es anhelada y recordada como una época única $e$ irrepetible por los habitantes y ex habitantes de la Población Explotadora. Y el contraste para consolidar esta dinámica rememorada lo daría el presente, en tanto contrapunto que permite ilustrar todo lo que se perdió. Es un espejo, un marco reflexivo desde el cual se interpreta, pero también 
se interpela un presente que posiblemente de otra manera se presentaría confuso y sin sentido.

\section{BIBLIOGRAFÍA}

Ambrosetti, D., Cvitanic, B., \& Matus, D. (2016). Población Obrera Sociedad Explotadora de Tierra del Fuego: expresión espacial de paternalismo industrial en Punta Arenas. Sophia Austral, 18, 111-135.

Bascopé, J. (2008). Pasajeros del poder proletario: La Sociedad Explotadora de Tierra del Fuego y la biopolítica estanciera (1890-1920). Magallania, 36(2), 19-44.

DOM (1952). Expediente $N^{\circ} 200$ Población Explotadora. Ilustre Municipalidad de Punta Arenas.

Godoy, M. (2015). Las casas de la empresa: paternalismo industrial y construcción de espacio urbano en Chile. Lota 1900-1950. Universum, 30(1), 115-136.

Halbwachs, M. (2004). La memoria colectiva. Prensa Universitaria Zaragoza, Zaragoza.

Mantecón, T. (2010). Formas de disciplinamiento social. Perspectivas Históricas. Revista de Historia Social y de las Mentalidades, 14(2), 263-295.

Martinic, M. (2006). Historia de la Región Magallánica. Punta Arenas: Ediciones de la Universidad de Magallanes.

Martinic, M. (2011). Recordando a un imperio pastoril: La Sociedad Explotadora de Tierra del Fuego (18931973). Magallania, 39(1), 5-32.
Mongin, O. (2006). La condición urbana. La ciudad a la hora de la mundialización. Buenos Aires: Paidós.

Organización Panamericana de la Salud \& Consejo de Organizaciones Internacionales de la Ciencia Médica. (2016). Pautas éticas internacionales para la investigación relacionada con la salud con seres humanos. Ginebra: Consejo de Organizaciones Internacionales de las Ciencias Médicas (CIOMS).

Sierra Álvarez, J. (1990). El obrero soñado. Ensayo sobre el paternalismo industrial (Asturias 1860-1917). Madrid: Siglo XXI.

\section{Entrevistas:}

Entrevistado 1. Realizada el 26 de mayo de 2017 en Sala reuniones Dpto. de Arquitectura Universidad de Magallanes

Entrevistada 2. Realizada el 29 de mayo de 2017 en residencia particular de la entrevistada

Entrevistada 3. Realizada el 30 de mayo de 2017 en residencia particular de entrevistada 2

\section{Taller Participativo:}

Realizado el 27 de mayo en la sede de la Junta de Vecinos de la Población Explotadora, que contó con la participación de 8 personas. 